simple circuit in which the alternator is replaced by a charged capacitor imposes upon the circuit breaker a test of almost equal severity to that produced by the machine. In this instance, an experimental gas. blast circuit breaker which has been employed regularly for breaking 1,100 amp. r.m.s. current from the $10,000-\mathrm{kW}$. alternator was tested on a circuit consisting of a $5-\mu \mathbf{F}$. capacitor in series with an inductance of $0.019 \mathrm{H}$., roughly equivalent to that of the machine, the capacitor having been charged to $10 \mathrm{kV}$. from a rectifier circuit. The circuit breaker found difficulty in clearing this circuit, although the peak current was only some $130 \mathrm{amp}$. as against the 1,550 amp. of the machine. The rate of change of current at the end of the first half-cycle is closely similar in the two cases, and the wave front of the re-striking voltage is substantially the same. It is thought that these observations are of significance in relation to the principles of are extinction and may lead to the development of 'synthetic' methods of circulfbreaker testing.

50

Work of the United States-Naval Observatory

THE results of observatidn made at the United States Naval Pofory with the 9-in. transit circle during the period $1935 \cdot 5-1945 \cdot 2$ have been issued as fublications of the United States Naval Observatory, Second Series, Vol. 15, Part 5 (Washingtop, 1948). The programme included: (1) observaton of the sun, Viercury, Venus, Mars, Jupiter, fafurn, Uranus, Neptune, 76 day stars, 225 clock $\mathrm{s} \mathrm{g} \mathrm{rs}$ and 36 azimuth stars; (2) ten observations of each of the stars north of $-36^{\circ}$ declination contained in a number of specified publications; (3) four observations of each of approximately 800 zodiacal stars fainter than mag. $7 \cdot 5$ contained in the "Albany General Catalogue" ; (4) six observations of each of about 3,000 stars, mag. $5 \cdot 5$ to about $8 \cdot 0$, uniformly spaced in the declination zone $0^{\circ}$ to $-30^{\circ}$; (5) about four observations of each star in a miscellaneous list, including 144 stars of the "International List" for the thirty-ninth parallel, 100 stars of the Washington photographic zenith tube list, and 113 stars, most faint or double stars not in the Yale re-observation of the Astronomische Gesellschaft zone, $-10^{\circ}$ to $-20^{\circ}$ declination. A detailed description is given of the personnel, instrumental equipment, general plan of observing, etc. Corrections to the equator and equinox were made, using the sun solutions, Mercury and Venus solutions, and Mars and Jupiter solutions; the results of the solutions of the combined normal equations in each case are given in Table 39 . It is expected that the catalogue will represent the results of the last programme to be conducted with the 9 -in. transit circle, which has been in service since 1865 , but which has been partially dismantled and will be replaced by a new instrument incorporating improvofl features.

\section{Earthquakes during April}

TwELVE strong arthquakes and many minor ones occurred dyrin April. The greatest was probably that which lappened on April 25 with strength $7 \frac{1}{2}$ and doth of focus $100 \mathrm{~km}$. near the coast of northern CKe It was felt at Iquique and at Arica and did damage to property in the village of Zapiga. An earthquake, not quite so strong, occurred on April 20 from a focus $70 \mathrm{~km}$. deep in southern Chile, and strongly affected the province of Bio-Bio. There were heavy casualties (at least fifty-seven dead and sixty injured) and property damage at Angol and
Traiguen; but other towns and villages, including Chillan, Concepcion and Los Anjeles, were also affected. The next strongest, and certainly the earthquake of deepest focus during the month, occurred on April 5, affecting an area near Vladivostok; the depth of focus was $550 \mathrm{~km}$. On April 13 a shock of instrumental scale just below 7 , and with a depth of focus rather greater than normal, caused considerable damage and some casualties over a wide area of the north-west Pacific coast of the United States. The epicentre was between Olympia and Tacoma in the State of Washington. In Seattle, buildings eracked, water mains were broken and two water tanks on the top of business buildings broke, cascading water into the streets. There were also damage and casualties at Portland, Oregon. Five persons have been reported killed and several injured by the earthquake. On April 24 an earthquake caused damage and casualties at Bandär-Abbas on the Persian Gulf. One of the minor shocks of the month happened on April 3 from an epicentre near Mons in Belgium, where it was felt with Mercalli scale 7. This recalls the earthquake of June 11, 1938, with epicentre between Oudenarde and Renaix according to O. Somville. This shock had maximum felt intensity 7 on the Mercalli-Cancani scale and displaced tiles from houses at Herne Bay, Kent. It was felt over a considerable area in Britain. Records have been received from the central stations at Strasbourg, Washington, D.C. (U.S. Coast and Geodetic Survey in co-operation with Science Service and the Jesuit Seismological Association) and Zurich, and stations at Cleveland (Ohio), De Bilt (Holland), Durham, Edinburgh, Kew, Stuttgart and Toledo.

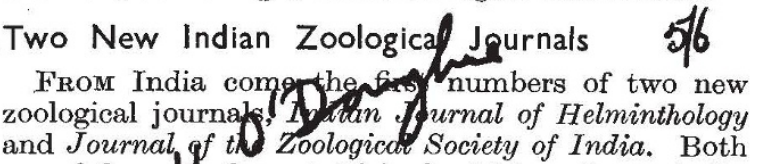
are of the saldo format, $7 \frac{1}{4}$ in. by $9 \frac{3}{4}$ in., of practically thess mo number of pages, 68 and 70 , respectively, and

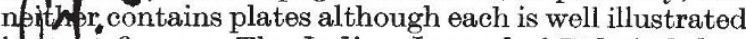
b. te t-figures. The Indian Journal of Helminthology was published in October 1948 under the editorship of Prof. Gobind Singh Thapar, who contributes the first paper in it, and it is sponsored by the recently formed Helminthological Society of India (Lucknow : Dept. of Zoology, University. Rs. 5 each issue). Of its six contributions, four are on helminths from fish, one on trematodes from birds and the remaining one on a cercaria from the freshwater snail, Melanoides tuberculatus. The cercaria, $C$. patialensis, is remarkable in several respects; inter alia, the brevifurcate tail has two processes arising from the region where it joins the body, and it possesses fully formed testes and ovaries with their respective ducts, and even motile sperms. The paper and type are good, and the wide margins give a pleasing appearance in these austere times. The Journal of the Zooloyical Society of India was published in January 1949, under the auspices of the Zoological Society of India (Calcutta), founded in 1939, and while at present it appears halfyearly, it is hoped to produce it quarterly. Its eleven contributions contain the annual address to the Society by Dr. M. L. Roonwall, and papers on fish, free-living and plant-parasitic nematodes, insects and ecology. It is closely printed, in two columns to the page with narrow margins, so that while not so pleasant to read as the other journal, it contains much more material. These journals will furnish additional outlets for Indian zoologists, and we wish them success. 